\title{
Complications and mortality after acute traumatic spinal cord injury in Saint Petersburg, Russia
}

\author{
Liudmila Mirzaeva $^{1} \cdot$ Sergey Lobzin ${ }^{1} \cdot$ Natalya Tcinzerling ${ }^{1} \cdot$ Andrey Sarana ${ }^{2,3} \cdot$ Nils Erik Gilhus ${ }^{4,5} \cdot$ Tiina Rekand $\circledast^{5,6}$
}

Received: 5 September 2019 / Revised: 18 March 2020 / Accepted: 18 March 2020 / Published online: 14 April 2020

(c) The Author(s), under exclusive licence to International Spinal Cord Society 2020

\begin{abstract}
Study design Retrospective cohort study.

Objectives We studied complications during early rehabilitation and their relation to length of stay (LOS) in the hospital as well as to survival in people with traumatic spinal cord injury (TSCI).

Setting All specialized hospitals of Saint Petersburg.

Methods We analysed all charts of patients admitted with acute TSCI to the city hospitals, 2012-2016. Patient characteristics, complications, time and cause of death, and LOS were recorded. Mean values with standard deviations and $t$-tests were used. We analysed mortality rate using the Kaplan-Meier method and calculated relative risks (RRs).

Results A total of 311 patients with TSCI were included. Complications occurred in 34\% of patients; most were respiratory complications and pressure ulcers. Complications occurred more often in those with concomitant traumatic brain injury $(\mathrm{TBI})(\mathrm{RR}=1.4,95 \% \mathrm{CI}: 1.2-1.8)$. All complications prolonged LOS (median, 11 days) and increased mortality in the acute phase $(p<0.001)$. In the early phase, $15 \%$ died, with a median time to death of 13 days. Respiratory complications markedly increased the death rate $(\mathrm{RR}=18,95 \% \mathrm{CI}: 15-22)$. Mortality rate correlated also with age, TSCI severity and level, and concomitant TBI. Alcohol/drug consumption before TSCI increased the likelihood for complications ( $\mathrm{RR}=1.7,95 \% \mathrm{CI}$ : $1.3-2.1)$ and mortality ( $\mathrm{RR}=2.2,95 \% \mathrm{CI}: 1.6-3.1)$.

Conclusion Focus on prevention as well as early and optimal treatment of complications, together with no or low alcohol/ drug consumption may reduce mortality in the early phase after TSCI and at the same time shorten LOS.
\end{abstract}

Tiina Rekand

tiina.rekand@helse-bergen.no

1 Department of Neurology, North-Western State Medical University, Saint Petersburg, Russia

2 Health Care Committee, Saint Petersburg, Russia

3 Saint Petersburg State University, Medical Faculty, Saint Petersburg, Russia

4 Department of Clinical Medicine, University of Bergen, Bergen, Norway

5 Department of Neurology, Haukeland University Hospital, Bergen, Norway

6 Institute for Clinical Neuroscience and Physiology, The Sahlgrenska Academy, University of Gothenburg, Gothenburg, Sweden

\section{Introduction}

Patients with traumatic spinal cord injury (TSCI) are at immediate risk of respiratory and cardiac failure, which can lead to death in the acute phase [1]. Secondary complications follow the ensuing loss of pulmonary function, loss of bladder control, or reduced mobility [2-5]. In addition, TSCI may cause dysfunction in almost every organ system because of autonomic failure, causing premature death [2]. Mortality rate is an important indicator of the economic and social burden of a disease and of treatment outcome [6]. The greatest improvement in TSCI survival has been achieved in the first year after an injury [2, 6, 7]. Preventive management and optimal treatment of complications are expected to improve outcome and survival. This is important as best estimates indicate that each year, there will be 170,000-250,000 new TSCIs globally, with an incidence rate of around 23 per million per year [1]. Injuries in general is now the fourth leading cause of global deaths, 
and up to 2030 World Health Organisation estimates a further $40 \%$ increase in trauma fatalities [8].

Complications are an important cause of mortality following SCI [2, 6, 9]. Despite advances in emergency and rehabilitation medicine, survival after TSCI seems to have remain unchanged in recent years [3]. The population of elderly persons with TSCI and with preexisting comorbidities has increased. This increase, together with recent care innovations, has altered the type and rate of complications as well as the causes of death in TSCI [9]. Causes of death in TSCI have changed over time, from being urinary tract disease and renal failure previously to cardiovascular disease and respiratory complications in recent years. Thus the causes of death in TSCI have become more similar to the causes of death in the general population $[10,11]$. However, there are still geographical differences, depending on local management. Mortality predictors differ among countries, and precise knowledge of such risk factors is important for planning strategies to improve general outcomes as well as long-term survival rates $[6,7]$.

There are no recent data on the frequency of TSCI complications and mortality rate in Saint Petersburg. We aimed to study the role of complications outside the nervous system related to patient characteristics during the initial rehabilitation period for TSCI. Such complications are less well studied than those from the nervous system, and they are important determinants for patient outcome. In addition, we analysed the relationship between complications and survival and identified possible risk factors.

\section{Methods}

\section{The Saint Petersburg region}

The area of Saint Petersburg is $1439 \mathrm{~km}^{2}$. The registered adult population (age $\geq 18$ years) was 4,267,500-4,400,500 (2012-2016) according to the Administration of the Federal State Statistics Service for Saint Petersburg and the Leningrad Region.

There are 13 hospitals with neurosurgical facilities in the city. According to the local legislation, only six hospitals have been certified to provide care for patients with acute TSCI. Therefore, such patients were transferred to these six hospitals for specialized treatment. We included the data not only from these six hospitals, but also from the other seven to find all patients and collect all available information.

The annual TSCI incidence rate for 2012-2016 was 16.6 per 1 million adults [12]. This figure is similar to those of other European countries, and lower than in the eastern regions of Russia, probably reflecting a more European lifestyle in Saint Petersburg [12-16].

\section{Inclusion criteria}

For this study, we included persons over age 18 years with acute TSCI (with ICD-10 codes S14, S24, and S34), admitted to 13 hospitals in Saint Petersburg, Russia, from January 1, 2012 to December 31, 2016 [12]. The group included all cases from the summary reports routinely presented to the Health Care Committee. To avoid missing patients due to misclassification, the following ICD10 codes were also covered in our search: $\mathrm{S} 12$ (S12.0, S12.1, S12.2, S12.7), S13 (S13.0, S13.1, S13.2, S13.4), S22 (S22.0), S23 (S23.0, S23.4), S32 (S32.0), S33 (S33.0, S33.1), G82, T06 (T06.0, T06.1), T08, T09.3, and T91 (T91.1, T91.3). The statistics department of each hospital assisted in identifying records with these ICD-10 codes. The first author of this paper analysed all the selected patient charts $(n=1517)$ to confirm the diagnosis. Acute TSCI was defined as an acute traumatic lesion of the spinal cord with varying degrees of motor and/or sensory deficit. Injury of the cauda equina was included. Clinical examinations (including AIS) were registered only by certified neurologists. The first author of this paper checked the congruence of the AIS-scales to the records in the charts for all included patients. The AIS score was changed only for three patients after reviewing the charts.

\section{Exclusion criteria}

Persons who died in the prehospital phase were not included in the study. Those with spinal fractures without spinal cord injury or with isolated injuries of nerve roots or autonomic nervous system manifestations only were excluded $(n=$ $1124)$, as were cases with missing key data for a precise diagnosis $(n=32)$. Of the remaining 361 cases that were all included when estimating the incidence of TSCI in Saint Petersburg [12], 50 cases with a lack of precise information about the severity and the level of injury were excluded in the present study.

\section{Chart data}

The following information was extracted from the hospital charts: sex and age, injury-related data (time, severity and level, cause, and concomitant injuries), use of alcohol and/or drugs, medical complications including the week of onset for each complication, death (time and immediate cause), and length of stay (LOS) in the hospital. Information on the following complications was obtained: respiratory complications, pressure ulcers, sepsis, urinary tract infections, postoperative infections, thromboembolism (including deep vein thrombosis and pulmonary embolism), and others, such as cardiovascular 
disturbances and infections in the thorax, nervous system, or bones. TSCI severity was determined using the American Spinal Injury Association Impairment Scale (AIS) for defining types of SCI [17]. Participants were grouped by age according to international guidelines, as follows: $18-29,30-44,45-59,60-74$, and $\geq 75$ years [17]. Alcohol or drug consumption was defined by presence of alcohol or drug in a blood sample taken shortly after the injury. We combined the groups of persons using alcohol and drugs into one joint group, as very few used only drugs and no alcohol, and several used both. Venous thromboembolism was diagnosed by the use of ultrasound and by lung X-ray including computer tomography, and at autopsy in deceased patients.

\section{Statistical analyses}

Data were collected into a Microsoft Excel spreadsheet. Descriptive statistical analyses were conducted using STATISTICA-10. Mean values with standard deviations (SDs) and median values with interquartile ranges (IQRs) were calculated. Differences between mean values were calculated using $t$-tests. The relationship between complications and mortality and nonmodifiable factors (sex, age, level, severity, cause, concomitant injury, and alcohol/drug consumption at the time of injury) was modeled using Cox's Proportional Hazards Method. Kaplan-Meier curves were used to visualize survival by groups with and without complications. Confidence intervals (CIs) were determined by the Clopper-Pearson method. Gehan's Wilcoxon test (for $n \geq 50$ ) and Cox's $F$-test (for $n<50$ ) were applied to study significance, which was defined as $p<0.05$. Relative risk (RR) was calculated using the formula: $\mathrm{RR}=\frac{a /(a+b)}{c(c+d)}$ (where $a$ is the number of deceased persons in the group with the complication, $b$ is the number of surviving persons in the group with the complication, $c$ is the number of deceased persons in the group without the complication, and $d$ is the number of surviving persons in the group without the complication). The median survival time has been calculated for all complications except urinary tract infections. The reason is the low rate of fatal outcome for this complication.

\section{Results}

Charts with complete information from 311 TSCI patients were analysed (Table 1). More men (72\%) than women $(28 \%)$ were included. The mean age (SD) at time of injury was 42 (16) years. The most frequent cause of TSCI was a fall $(50 \%)$, followed by motor vehicle accidents (19\%). Surgical treatment was performed in $74 \%$ of cases $(40 \%$ within $24 \mathrm{~h}$ after acute hospitalization, $60 \%$ after $24 \mathrm{~h}$ );
Table 1 Characteristics of all traumatic spinal cord injury (TSCI) persons and of those who died during the primary hospital stay (deceased persons).

\begin{tabular}{|c|c|c|c|c|}
\hline \multirow[t]{2}{*}{ Characteristics } & \multicolumn{2}{|c|}{$\begin{array}{l}\text { All persons } \\
(n=311)\end{array}$} & \multicolumn{2}{|c|}{$\begin{array}{l}\text { Deceased } \\
\text { persons } \\
(n=46)\end{array}$} \\
\hline & $n$ & $\%$ & $n$ & $\%$ \\
\hline \multicolumn{5}{|l|}{$\operatorname{Sex}$} \\
\hline Male & 224 & 72 & 37 & 80 \\
\hline Female & 87 & 28 & 9 & 20 \\
\hline \multicolumn{5}{|l|}{ Age (years) } \\
\hline $18-29$ & 85 & 27 & 8 & 17 \\
\hline $30-44$ & 92 & 30 & 12 & 26 \\
\hline $45-59$ & 75 & 24 & 13 & 28 \\
\hline $60-74$ & 43 & 14 & 9 & 20 \\
\hline$\geq 75$ & 16 & 5 & 4 & 9 \\
\hline Age at injury; mean (SD) & $42(16)$ & $49(18)$ & & \\
\hline \multicolumn{5}{|l|}{ Cause } \\
\hline High falls & 106 & 34 & 14 & 30 \\
\hline Low falls & 50 & 16 & 6 & 13 \\
\hline Motor vehicle accidents & 58 & 19 & 14 & 30 \\
\hline Sport & 11 & 4 & 0 & 0 \\
\hline Diving & 19 & 6 & 3 & 6.5 \\
\hline Violence & 19 & 6 & 1 & 2 \\
\hline Other & 20 & 6 & 3 & 6.5 \\
\hline Unknown & 29 & 9 & 5 & 11 \\
\hline \multicolumn{5}{|l|}{ Level } \\
\hline Cervical & 160 & 51 & 36 & 78 \\
\hline Thoracic & 74 & 24 & 5 & 11 \\
\hline Lumbar/sacral & 77 & 25 & 5 & 11 \\
\hline \multicolumn{5}{|l|}{ AIS grade } \\
\hline AIS A & 49 & 16 & 21 & 46 \\
\hline AIS B & 48 & 15 & 11 & 24 \\
\hline AIS C & 56 & 18 & 9 & 20 \\
\hline AIS D & 149 & 48 & 2 & 4 \\
\hline Unknown & 9 & 3 & 3 & 6 \\
\hline \multicolumn{5}{|l|}{ Concomitant TBI } \\
\hline No & 188 & 60 & 20 & 43 \\
\hline Yes & 123 & 40 & 26 & 57 \\
\hline \multicolumn{5}{|l|}{ Complications } \\
\hline No & 206 & 66 & 2 & 4 \\
\hline Yes & 105 & 34 & 44 & 96 \\
\hline Alcohol or drugs consumption before TSCI & 51 & 16 & 14 & 30 \\
\hline \multicolumn{5}{|l|}{ Acute surgical treatment } \\
\hline No & 82 & 26 & 8 & 17 \\
\hline Yes & 229 & 74 & 38 & 83 \\
\hline (Within $24 \mathrm{~h}$ ) & (92) & (40) & & \\
\hline (After $24 \mathrm{~h}$ ) & (137) & (60) & & \\
\hline
\end{tabular}

Descriptive statistics were used. The percentage was calculated on the basis of $100 \%$ in total in each category (sex, age, cause, level, AIS grade, concomitant TBI, complications, alcohol/drugs consumption before TSCI, acute surgical treatment).

$S D$ standard deviation, High falls falls from a height $>1 \mathrm{~m}$, Low falls falls from a height $\leq 1 \mathrm{~m}, A I S$ American Spinal Injury Association Impairment Scale, TBI traumatic brain injury.

among those with severe injuries and AIS A or AIS B surgery was performed in $90 \%$, with AIS C in $77 \%$, and with AIS D with surgical treatment in $62 \%$. 


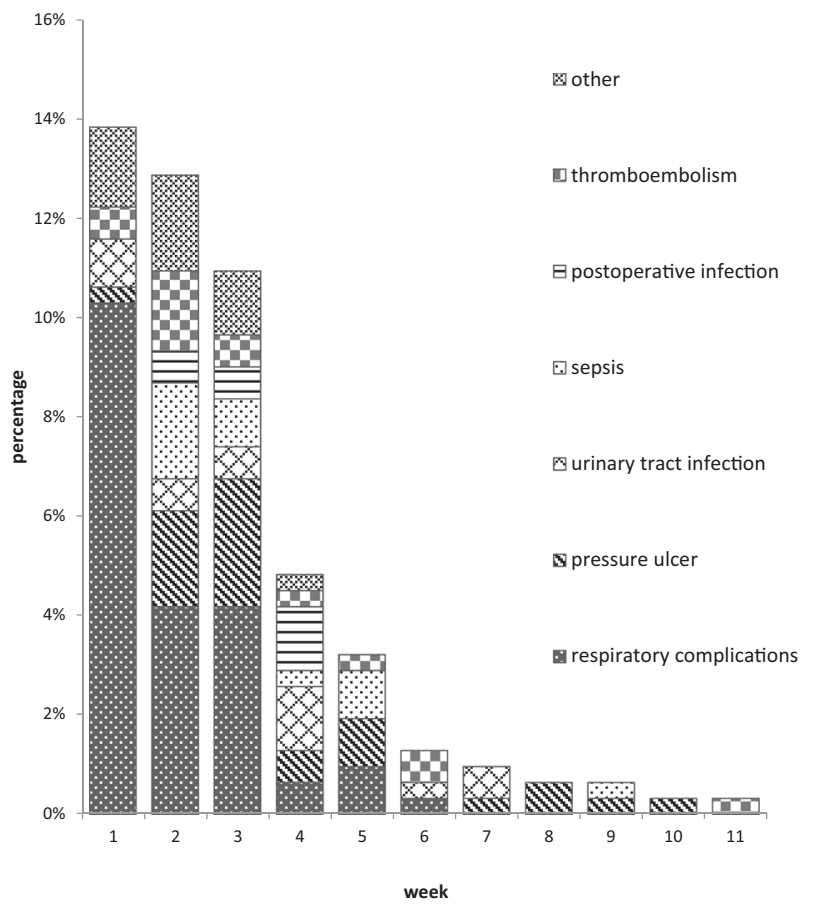

Fig. 1 Complications during the hospitalisation. Frequency of complications by week after traumatic spinal cord injury (TSCI).

\section{Acute complications}

In total, 105 cases $(34 \%)$ had at least one complication during the acute primary stay for TSCI at the hospital. By age, $50 \%$ of those over 75 years had complications, compared with $30-35 \%$ in the younger age groups $(p<0.05)$. No sex differences in complication rates were observed. In 54 cases $(51 \%)$, there was only one complication, and the remaining cases involved two or more. Respiratory complications were the most common.

Complications were most frequent during the first 4 weeks after injury (Fig. 1). The overall incidence of complications according to TSCI severity was as follows: AIS A, 76\%; AIS B, 58\%; AIS C, 46\%; and AIS D, 7\%. Specified complication rates according to severity are shown in Fig. 2a. Respiratory complications occurred in $61 \%$ of cases with complete TSCI injury (AIS A), in $42 \%$ of AIS B, and in $25 \%$ of AIS C, but in only $4 \%$ of AIS D cases $(p<0.001)$. Pressure ulcers similarly occurred less frequently in group AIS D (1.3\%) compared with groups AIS A (22\%), AIS B (25\%), and AIS C $(9 \%), p<0.001$. Sepsis in group AIS D was less frequent (1\%) than in groups AIS A (18\%), AIS B (8\%), and AIS C (7\%), $p<0.01$. Urinary tract infections were most common in cases with complete SCI AIS A (10\%), higher than in group AIS D (2\%), $p<$ 0.05 . No thromboembolic complications were observed in persons of group AIS D, with no significant differences between groups AIS A, B, and C. The frequency of postoperative infections was similar in all AIS groups.
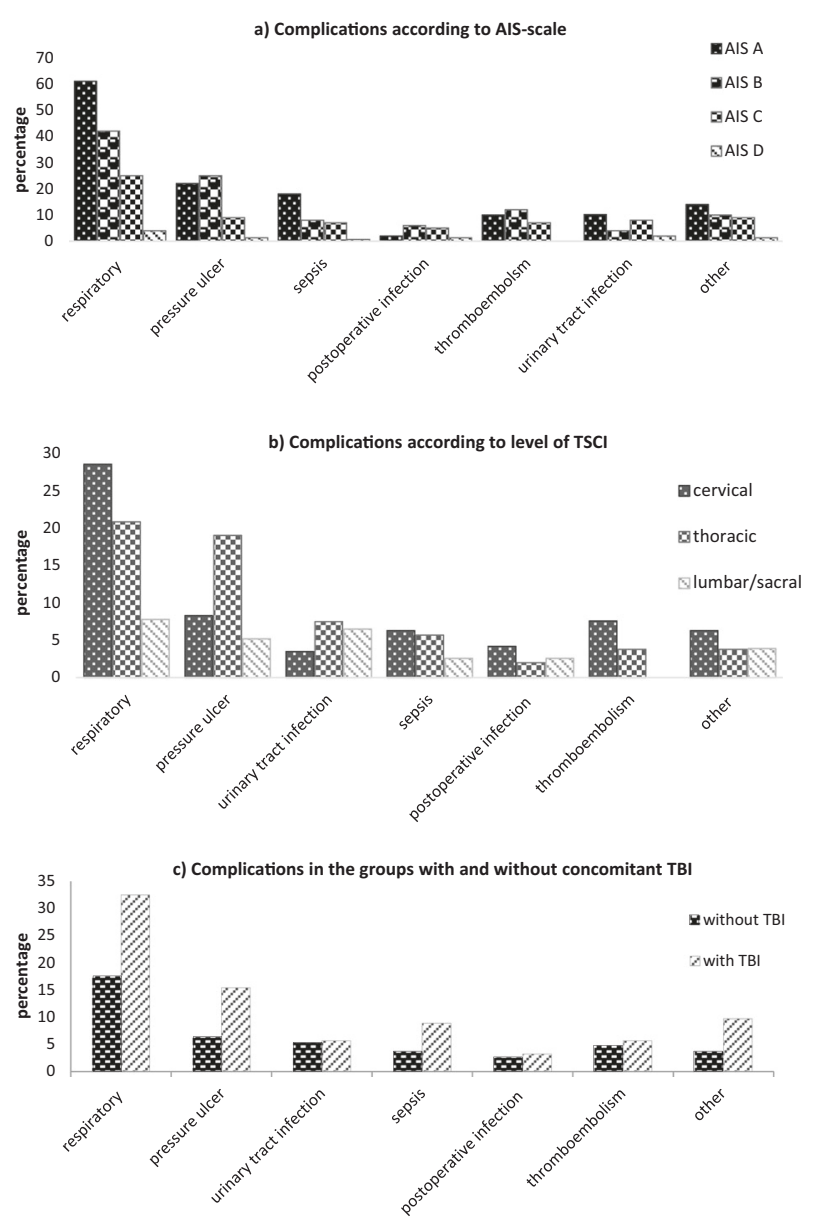

Fig. 2 Clinical features and complications. Characteristics of traumatic spinal cord injury (TSCI) and frequency of complications.

The lowest complication frequency $17 \%$ was associated with TSCI at the lumbar/sacral level, whereas the complication rate was $39 \%$ for cervical and thoracic TSCI combined $(p<0.05)$. Respiratory complications developed more often in persons with cervical $(29 \%)$ and thoracic $(21 \%)$ damage compared with lumbar/sacral level $(8 \%), p<0.05$. The second most common complication, pressure ulcers, was seen most often in individuals injured at the thoracic level (in 19\% of cases), Fig. $2 b(p<0.05)$. The frequency of sepsis, as well as urological and postoperative infections, did not depend on the TSCI level. Thromboembolism occurred in $5 \%$ of cases, and rates differed depending on TSCI level, in 13 cases (8\%) among those with cervical TSCI, 3 cases (4\%) with thoracic, and none for lumbar/ sacral TSCI $(p<0.05)$.

Concomitant traumatic brain injury (TBI) occurred in $40 \%$ of persons with TSCI (Table 1), most often during motor vehicle accidents (67\%). One half of patients with concomitant TBI had additional lesions outside the central nervous system. TBI was more common at a young age; rates by age were $45 \%$ at $18-29$ years; $41 \%$ at $30-44$ years; $43 \%$ at $45-59$ years $43 \% ; 21 \%$ at $60-74$ years; and $38 \%$ 
Table 2 Risk factors for complications and death in patients with traumatic spinal cord injury (TSCI).

\begin{tabular}{|c|c|c|c|c|c|c|}
\hline \multirow[t]{2}{*}{ Factor } & \multicolumn{3}{|c|}{ Complications } & \multicolumn{3}{|l|}{ Death } \\
\hline & Chi square & $\begin{array}{l}\text { Hazard ratio } \\
(95 \% \mathrm{CI})\end{array}$ & $p$ value & Chi square & $\begin{array}{l}\text { Hazard ratio } \\
(95 \% \mathrm{CI})\end{array}$ & $p$ value \\
\hline Sex (male vs female) & 0.03 & $1.0(0.7-1.6)$ & 0.863 & 1.7 & $1.6(0.8-3.4)$ & 0.196 \\
\hline Cause (MVA vs other causes) & 1.1 & $1.0(0.9-1.2)$ & 0.284 & 0.2 & $1.0(0.9-1.2)$ & 0.648 \\
\hline $\begin{array}{l}\text { Age (age group } \geq 45 \text { years vs } \\
<45 \text { years) }\end{array}$ & 2.4 & $1.0(0.9-1.1)$ & 0.113 & 5.1 & $2.0(1.1-3.6)$ & 0.024 \\
\hline Alcohol/drug (yes vs no) & 5.5 & $1.7(0.7-2.2)$ & 0.018 & 4.1 & $1.4(1.0-2.0)$ & 0.042 \\
\hline TBI (yes vs no) & 4.6 & $1.4(1.0-1.8)$ & 0.031 & 7.1 & $1.4(1.1-1.8)$ & 0.007 \\
\hline Injury level & 12 & $0.6(0.5-0.8)$ & 0.000 & 13 & $0.4(0.2-0.7)$ & 0.000 \\
\hline $\begin{array}{l}\text { Cervical vs thoracic, lumbar- } \\
\text { sacral }\end{array}$ & 12 & $2.6(1.4-4.8)$ & 0.001 & 16 & $3.9(1.5-10)$ & 0.000 \\
\hline Cervical vs thoracic & 5.5 & $1.8(1.1-2.8)$ & 0.018 & 9.9 & $4.6(1.8-12)$ & 0.002 \\
\hline Cervical vs lumbar-sacral & 10 & $2.8(1.5-5.1)$ & 0.001 & 16 & $4.0(1.6-10)$ & 0.003 \\
\hline Thoracic vs lumbar-sacral & 1.1 & $1.4(0.7-2.8)$ & 0.046 & 2.5 & $0.9(0.3-3.3)$ & 0.104 \\
\hline AIS grade & 18 & $0.7(0.5-0.8)$ & 0.000 & 29 & $0.4(0.3-0.6)$ & 0.000 \\
\hline AIS A vs AIS B, C, D & 9.8 & $4.2(2.0-8.6)$ & 0.001 & 23 & $21(5.7-75)$ & 0.000 \\
\hline AIS B vs AIS C, D & 3.4 & $3.9(1.9-8.2)$ & 0.027 & 2.0 & $11(2.5-54)$ & 0.012 \\
\hline AIS A vs AIS B & 0.9 & $1.3(0.8-2.1)$ & 0.351 & 5.5 & $2.5(1.2-5.3)$ & 0.018 \\
\hline AIS A vs AIS C & 2.5 & $1.5(0.9-2.6)$ & 0.116 & 7.2 & $2.9(1.3-6.5)$ & 0.007 \\
\hline AIS A vs AIS D & 24 & $6.3(3.0-13)$ & 0.000 & 21 & $30(7.0-128)$ & 0.000 \\
\hline AIS B vs AIS C & 0.9 & $1.3(0.7-2.3)$ & 0.347 & 0.5 & $1.4(0.6-3.6)$ & 0.473 \\
\hline AIS B vs AIS D & 7.5 & $2.9(1.3-6.1)$ & 0.006 & 7.4 & $8.6(1.8-41)$ & 0.006 \\
\hline AIS C vs AIS D & 6.2 & $2.7(1.2-5.7)$ & 0.012 & 5.8 & $6.8(1.4-33)$ & 0.016 \\
\hline
\end{tabular}

Cox's Proportional Hazards Method was used to search for risk factors for complications and death. Chisquare, hazard ratio of each factor and significance were determined. The results are considered significant at $p<0.05$.

$v s$ versus, TBI traumatic brain injury, AIS American Spinal Injury Association Impairment Scale. among those $\geq 75$ years. Complications in general were more frequent with concomitant $\mathrm{TBI}(\mathrm{RR}=1.4,95 \% \mathrm{CI}$ : $1.1-1.8 ; p<0.05)$, especially for respiratory complications $(\mathrm{RR}=1.8,95 \% \mathrm{CI}: 1.4-2.3)$, pressure ulcers $(\mathrm{RR}=2.7$, 95\% CI: 1.7-3.4) and sepsis ( $\mathrm{RR}=2.3$, 95\% CI: $1.4-3.5)$, $p<0.01$; Fig. 2c. Spine surgery was equally common in those without and with TBI $(\mathrm{RR}=1.1,95 \% \mathrm{CI}$ : 0.9-1.2, $p=0.42$ ).

LOS was significantly prolonged in patients with TSCI and complications: median LOS (IQR) was 19 (10-31) days for all TSCI patients (range: 1-86 days), but 28 (14-53) days for patients with complications versus 17 (10-24) days for patients without complications $(p<0.001)$. LOS did not differ between individuals under age 60 years and those above 60 years: 19 (10-32) days versus 20 (12-28) days. LOS did not differ among participants in groups AIS A, AIS B, and AIS C (median 21 [6-35] days, 28 [17-45] days, 25 [16-41] days, respectively. LOS among participants in the group with mild injury, AIS D, was shorter (median 15 [9-23] days) than in group AIS A $(p<0.001)$.

Complications occurred in $51 \%$ of cases among individuals with alcohol or drug consumption during the last $24 \mathrm{~h}$ before their TSCI, but only in $30 \%$ without $(\mathrm{RR}=1.7,95 \%$ CI: 1.3-2.1), $p<0.05)$.

Relation between risk factors for complications and death were studied with Cox's Proportional Hazards Models (Table 2).

\section{Mortality}

Of the 311 patients with TSCI, 46 (15\%) died in hospital during the initial stay. Three of them died within $24 \mathrm{~h}$ after admission. In most cases, death occurred in the first and second weeks (median [IQR], 13 [4-23] days). The main causes of death (according to autopsy reports) were cardiovascular $(n=6)$, respiratory insufficiency $(n=8)$, failure in multiple organs $(n=9)$, pulmonary thromboembolism $(n=6)$, myocardial infarction $(n=2)$, infections (sepsis, meningoencephalitis, and peritonitis) $(n=10)$, and edema in the central nervous system $(n=5)$.

Three patients died as a direct result of their TSCI (spinal cord edema, based on autopsy reports). Respiratory complications increased the mortality rate, to $53 \%$. If sepsis occurred, the death rate increased even more, to $67 \%$. If 
Table 3 Risk of complications and risk of death during the primary hospital stay after acute traumatic spinal cord injury (TSCI).

\begin{tabular}{llllr}
\hline Complications & $n$ & $\begin{array}{l}\text { Risk of complication }(\% \text { and } \\
95 \% \text { CI })\end{array}$ & $\begin{array}{l}\text { Risk of death }(\% \text { and } \\
95 \% \text { CI })\end{array}$ & RR (95\% CI) \\
\hline All & 105 & $34(29-39)$ & $42(32-52)$ & $43(40-46)$ \\
Respiratory complications & 73 & $24(19-29)$ & $53(41-65)$ & $18(15-22)$ \\
Pressure ulcer & 31 & $10(6.9-14)$ & $32(17-51)$ & $2.5(1.7-3.6)$ \\
Sepsis & 18 & $5.8(3.5-9.0)$ & $67(41-87)$ & $5.7(4.0-7.9)$ \\
Urinary tract infection & 17 & $5.5(3.2-8.6)$ & $29(10-56)$ & $2.1(1.2-3.5)$ \\
Thromboembolism & 16 & $5.1(3.0-8.2)$ & $81(54-96)$ & $7.3(5.2-9.8)$ \\
Postoperative infection & 9 & $2.9(1.3-5.4)$ & $33(7-70)$ & $2.3(1.1-4.4)$ \\
Other complications & 19 & $6.1(3.7-9.4)$ & $79(54-94)$ & $7.4(5.4-9.9)$ \\
\hline
\end{tabular}

Risk of complication (percentage) and risk of death (percentage of death in cases with complications) are given with $95 \%$ confidence intervals (CI); it was determined the ratio of a fatal outcome probability occurring in a group with complication, compared with a fatal outcome probability occurring in a group without complication.

$R R$ relative risk. experiencing a thromboembolic episode, mortality was $81 \%$ (Table 3). Complications in general increased mortality to $42 \%$. Having multiple complications increased the mortality rate by 2.5 times compared with only one complication $(\mathrm{RR}=2.5,95 \% \mathrm{CI}: 1.3-3.9, p<0.01)$. The impact of complications on survival for the total group of patients is shown in Fig. 3.

The mortality rate was 9\% among those aged 18-29 years, $13 \%$ for age $30-44$ years, $17 \%$ at $45-59$ years, $21 \%$ at $60-74$ years, and $23 \%$ above 75 years. The mean (SD) age of the deceased patients was 49 (18) years, and median (IQR) was 54 (32-62) years. The mean (SD) age of the surviving patients was 42 (16) years, and median (IQR) 38 (27-53) years $(p<0.01)$. Complications in general seemed to influence mortality more in the older age groups, but this difference was not significant $(p=0.08)$.

Mortality rate was higher with TSCI at the cervical level than among individuals affected at the thoracic and lumbar/ sacral levels $(\mathrm{RR}=3.4,95 \% \mathrm{CI}: 2.6-4.4, p<0.001)$. Among the deceased patients, 36 (78\%) had TSCI at the cervical level.

Mortality rate was $43 \%$ among study participants in group AIS A, 23\% in group AIS B, $9 \%$ in group AIS C, and $1 \%$ in group AIS D $(p<0.05)$. In-hospital mortality rate was the highest with TSCI after motor vehicle accidents, at $24 \%$ compared with $16 \%$ for diving accidents and $13 \%$ after falls. Mortality rates were similar for falls from a high or a low height. There were no fatal cases after sports injuries. Mortality differences by TSCI cause could be explained by variation in TSCI level and severity, along with concomitant TBI. Mortality rate was higher in cases with TBI than without $(\mathrm{RR}=1.9,95 \% \mathrm{CI}: 1.4-2.6, p<0.05)$.

Alcohol/drug consumption within $24 \mathrm{~h}$ before a TSCI was documented in $30 \%$ of deaths, which was higher than among the survivors $(14 \%, \mathrm{RR}=2.2,95 \% \mathrm{CI}$ : $1.6-3.1 ; p<0.05)$.

\section{Discussion}

The main findings in this study are that $34 \%$ of patients with TSCI had at least one complication outside the nervous system and half of them had two or more complications. We have shown the importance of such complications for LOS and mortality rate, as well as identified risk factors for these complications. Similar previous studies have yielded higher complication rates; e.g., from Sweden [4], with $78 \%$ of participants having had at least one complication; The Netherlands, with 59\% [18]; and South Africa, with more than $50 \%$ of the cohort [19]. In contrast, findings from a US study suggested a lower complication rate of $26 \%$ [20]. These differences could result from varying sensitivity for detecting and reporting complications but also reflect differences in patient cohorts and treatment. Our study focused not only on complication frequency but also and more importantly on how they affected survival. We found that all complications influenced survival but that respiratory complications were most influential. The most common complications were from the respiratory tract (24\%) and pressure ulcers (10\%). Our study confirmed that patients with AIS A and AIS B are most prone to respiratory complications and pressure ulcers.

Our results differ from previous studies regarding the frequency of different complications. A study from Tanzania [1] showed that pressure ulcers were the most frequent $(20 \%)$ in that cohort, followed by respiratory complications (15\%). In a population from South Africa [19], pressure ulcers occurred in $30 \%$ and pulmonary complications in 23\%. Findings from The Netherlands were similar [18] demonstrating that pressure ulcers $(31 \%)$ and pulmonary complications (28\%) being most common. In a US study, at least one pressure ulcer developed in $37 \%$ of patients during acute-care hospitalization [21]. We found a lower frequency of pressure ulcers, similar to a study in Canada [22]. 
Cumulative Proportion Surviving (Kaplan-Meier)

$\circ$ deceased + survived

- - - no complication

- all complications ( $\mathrm{M}=65$, CI: 55-74, $\mathrm{p}<0.001$ )

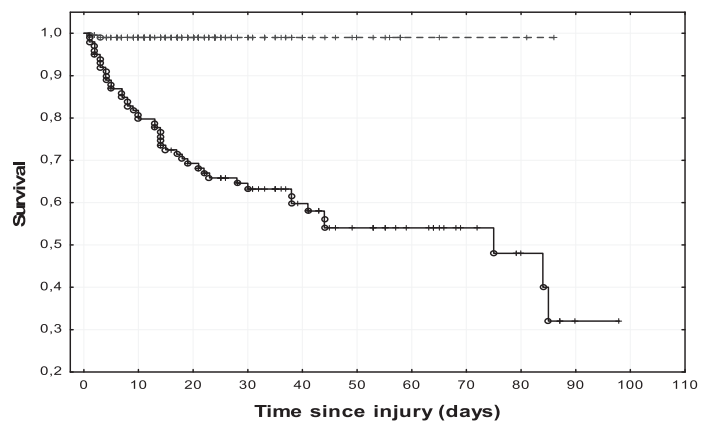

- - - no thromboembolism

- thromboembolism ( $\mathrm{M}=21 \mathrm{CI}: 14-30, \mathrm{p}<0.001)$

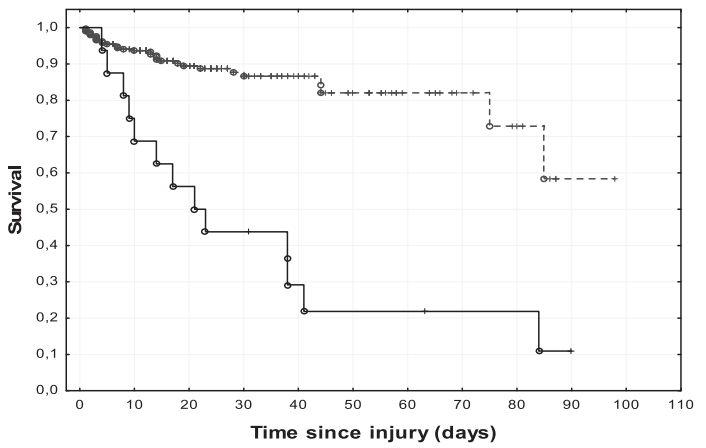

- - - no other complications

- other complications $(M=14, C I: 9-22, p<0.001)$

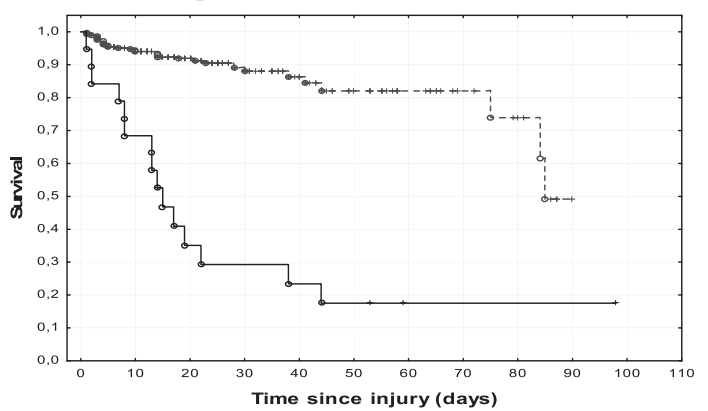

- - - no postoperative infection

- postoperative infection ( $M=85$, CI: 77-91, $p=0.35$ )

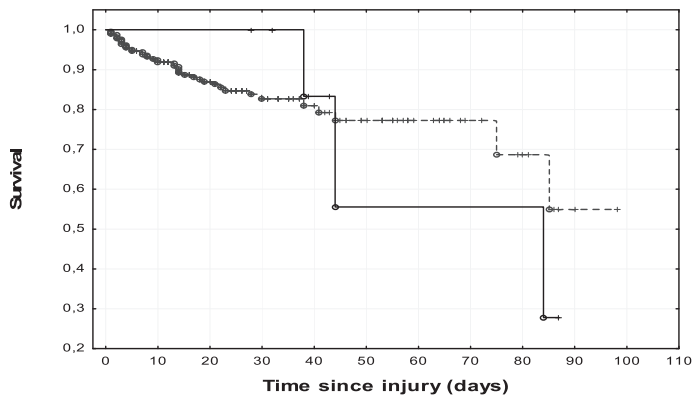

- - - no respiratory complications

— respiratory complic. ( $\mathrm{M}=38$, CI: 29-48, $\mathrm{p}<0.001)$

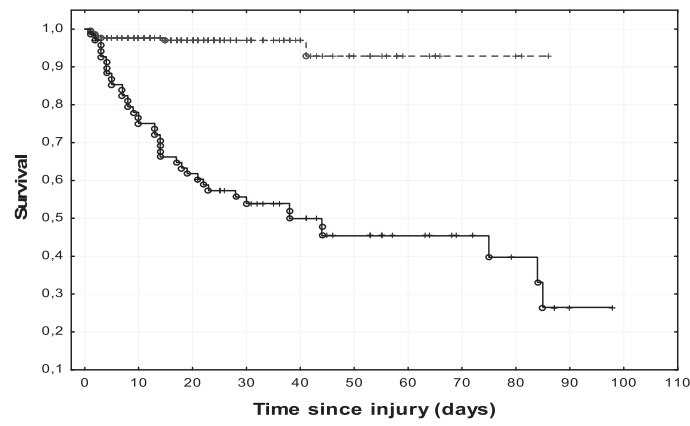

- - - no sepsis

- sepsis $(M=44$, CI: 35-54, $p<0.05)$

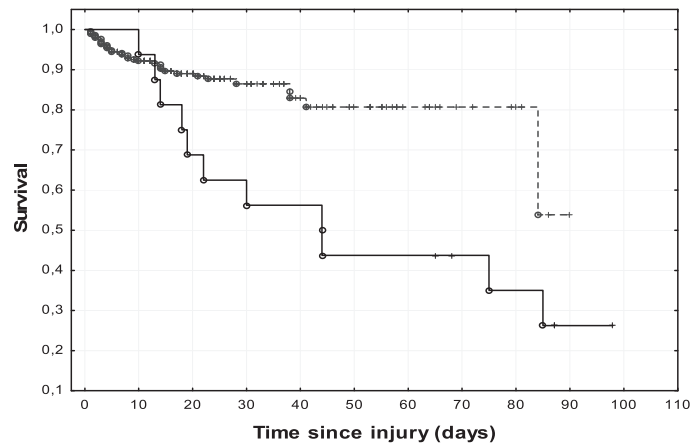

- - - no pressure ulcer

- pressure ulcer $(\mathrm{M}=78, \mathrm{CI}: 69-85, \mathrm{p}=0.29)$

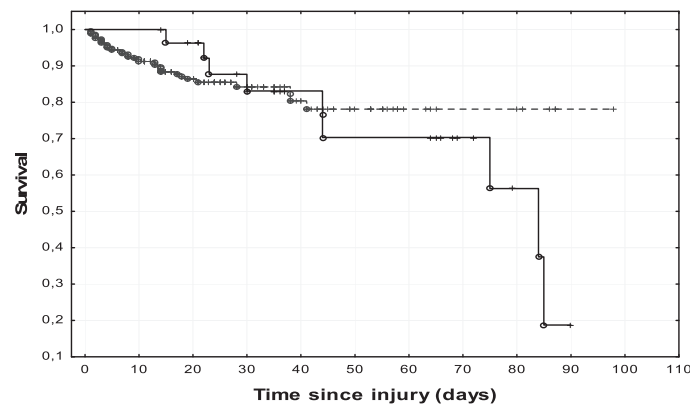

- - - no urinary tract infection

- urinary tract infection $(p=0.39)$

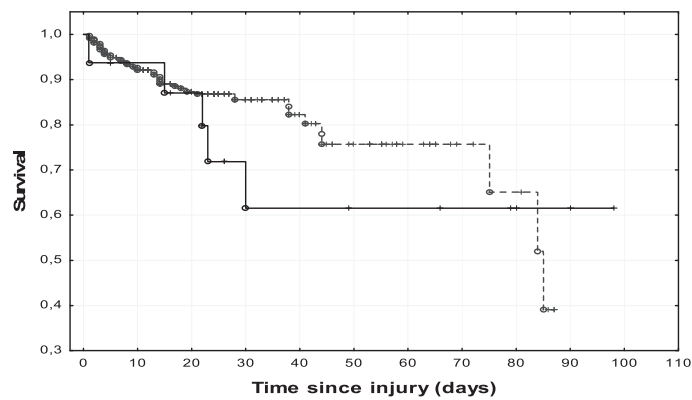

Fig. 3 Complications and survival. Survival after traumatic spinal cord injury (TSCI) in relation to complications. 
Frequency of pressure ulcers reflects organization and quality of care [3]. It is important to focus on registration of all phases of pressure ulcers, including phase 1 (only red skin areas). In our study, only pressure ulcers in stage 2-4 (visible pressure ulcers) have been systematically recorded in the patient charts.

We identified a low frequency of urinary tract infections (5.5\%) compared with previous studies [4, 19, 22, 23]. However, similarly low frequencies were reported for patients in The Netherlands [18] and in a previous study from Russia [24]. Urinary tract infections are associated with completeness of injury (more frequent in persons with complete injury-AIS A) [19] and depend on the quality of bladder management (intermittent catheterization is a safe and effective treatment for neurogenic bladder dysfunction caused by SCI) [23]. Our data reflect the low incidence of complete injuries and a close attention to the Russian guidelines for treatment and prevention of TSCI complications, including intermittent catheterization, regular use of antibiotics, and uroseptics (palin, urodan, urolesan, and canephron), and bladder irrigation with dioxidine [25]. It is also possible that some cases of mild urinary tract infection were not recorded in the patient charts.

Despite our routine prophylaxis of thromboembolism, the frequency of this complication remained high (5\%). It was more common for cervical TSCI, in contrast to the US data showing the highest rate for thoracic TSCI [26].

The frequency of complications increased with age and with higher level and severity of injury, similar to previous reports [2]. Our findings differ from a study from Sweden, however, showing associations between the level of injury and complications during acute care [4]. Older age and injury level and severity should be defined as risk factors for complications. We found that the frequency of complications was the highest during the first month after injury. Patients with cervical TSCI and complete injuries should be monitored especially closely for complications, and in particular those related to respiratory function.

Increased mortality with age may be associated with comorbidity, and older patients with TSCI should be attentively examined for complications. In the acute TSCI phase, prevention of complications is the most important task.

The median hospital LOS for TSCI in different studies varies from several days to several months and depends on many factors: the severity or completeness of injury, the presence of complications or risk of their development, and organization of medical care for TSCI patients in various countries [1, 5, 19, 23]. In a study from South Africa, median LOS was comparable to our study, 24 days (range: 3-245 days) [19]. In Latvia, the median LOS was 39 days (range: 5-104 days) [23]. A study from Canada noted that the LOS depended on age, with a median of 28 days in the younger age group and 35 days in the group of elderly patients [5]. Moshi et al. (Tanzania) indicate that LOS was shorter in the group with complications $(46.7 \pm 37.8$ days $)$ than in those without complications $(75.7 \pm 60.2$ days) [1]. We found that complications increased LOS regardless of patient age and were more important than TSCI severity. Based on these results, optimal prevention and management of complications should reduce LOS.

TBI occurred frequently, identified in $40 \%$ of our cases, similar to studies from Norway, USA, and Russia $[25,27,28]$. Persons with TBI had more respiratory complications and sepsis. The persons with TSCI and TBI should have frequent checks for complications.

Alcohol and drug consumption has been identified as a risk factor for complications and mortality. A US study [29] showed that alcohol increased the risk for all complications but did not affect mortality. Another study found that alcohol and substance abuse was a predictor of TSCI mortality [30], in keeping with our findings. Prevention of these habits should have a marked positive effect on the frequency of complications and survival after TSCI.

The mortality rate in our study was $15 \%$, similar to previous results from a Russian population [31]. Reported early mortality rates with TSCI range from 0 to $38 \%$, which is a wide span, most likely because of differences in study design. Studies with higher mortality usually had longer follow-up periods [6]. Complications were an important marker for mortality in our study, as previously reported $[2,7]$. The mortality rate was $42 \%$ in cases with complications but only $1 \%$ with no complications. The first 4 weeks after an acute TSCI were most critical. Although the causes of death were both neurological and non-neurological, our data, in line with previous TSCI studies $[6,11,32]$, show that mortality correlates with occurrence of complications, age, and TSCI severity and level.

Respiratory evaluation and the use of appropriate respiratory aids are probably the single most important precaution to reduce TSCI mortality. Prophylactic use of anticoagulant therapy should be routinely performed for 3 months after TSCI to reduce the risk of thromboembolism [33].

Our study had some limitations. Those who died at the prehospital stage, as well as those who were injured outside the city and never brought back to Saint Petersburg (because of discharge or death), were not included. Such missing cases are relatively few, but may have influenced the final results through selection bias. Some included cases had incomplete data. Due to the retrospective design of our study, it has not been possible to confirm the accuracy in registration of complications and reanalyze the causes of death. Only visible pressure ulcers (stages 2-4) have been counted. We combined the persons using alcohol and drugs into one group, as the group of people who used only drugs 
was very small. There were many cases with both drug and alcohol use. Due to inconsistent and unreliable information we were not able to quantify alcohol and drug intake.

\section{Conclusions}

Non-neurological complications occurred in $34 \%$ of patients with TSCI in this study, and the most common involved the respiratory tract and were pressure ulcers. Early mobilization reduces complication rates [2-5], reflected also in our data, showing a higher frequency of complications among patients with less mobility due to complete or cervical SCI. Complications prolonged LOS and increased mortality. Higher age, upper TSCI level (cervical, thoracal), and more severe TSCI increased the frequency of complications. Concomitant TBI and alcohol/ drug consumption before the injury, as well as cervical TSCI were associated with increased mortality. Risk assessment and individual evaluation of patients with TSCI are necessary to minimize complications and for optimal use of available resources. Preventive management and optimal treatment of complications together with no or low alcohol/drug consumption could reduce TSCI mortality and shorten LOS.

\section{Data availability}

The datasets generated and analysed during the current study are available from the corresponding author on request.

Acknowledgements We thank A. Dulaev, T. Skoromets, V. Dorofeev, S. Petrov, Y. Linets, G. Sokurenko, and V. Rybnikov for their help in finding medical records. We are grateful to statistician O. Klicenko for her help.

Funding The study was supported by a grant from the Norwegian Centre for International Cooperation in Education.

Author contributions LM was responsible for searching for and collecting data, statistical analysis, the literature search, and preparation and revision of the paper. SL was responsible for the design, organization, and management of the research and approval of the final version. NT was responsible for organization, the literature search, and revision of the paper. AS was responsible for obtaining information from the Health Care Committee and hospitals. NEG was responsible for preparation and revision of the paper, evaluation of methods, and approval of the final version. TR was responsible for study design, creating tables and figures, the literature search, interpreting the results, and preparation and revision of the paper.

\section{Compliance with ethical standards}

Conflict of interest The authors declare that they have no conflict of interest.
Ethical approval The study was approved by the Research Ethics Committee of the North-Western State Medical University, named after I.I. Mechnikov, Saint Petersburg, Russia (No 10/date 09.11.2016).

Publisher's note Springer Nature remains neutral with regard to jurisdictional claims in published maps and institutional affiliations.

\section{References}

1. Moshi H, Sundelin G, Sahlen K-G, Sörlin A. Traumatic spinal cord injury in the north-east Tanzania-describing incidence, etiology and clinical outcomes retrospectively. Glob Health Action. 2017. https://doi.org/10.1080/16549716.2017. 1355604

2. Haisma JA, van der Woude LH, Stam HJ, Bergen MP, Sluis TA, Post MW, et al. Complications following spinal cord injury: occurrence and risk factors in a longitudinal study during and after inpatient rehabilitation. J Rehabilit Med. 2007;39:393-8.

3. Zakrasek EC, Creasey G, Crew JD. Pressure ulcers in people with spinal cord injury in developing nations. Spinal Cord. 2015; 53:7-13.

4. Wahman K, Nilsson Wikmar L, Chlaidze G, Joseph C. Secondary medical complications after traumatic spinal cord injury in Stockholm, Sweden: towards developing prevention strategies. J Rehabilit Med. 2019;51:513-7.

5. Ahn H, Bailey CS, Rivers CS, Noonan VK, Tsai EC, Fourney DR, et al. Effect of older age on treatment decisions and outcomes among patients with traumatic spinal cord injury. CMAJ. 2015; 187:873-80.

6. Azarhomayun A, Aghasi M, Mousavi N, Shokraneh FR, Vaccaro A, Haj Mirzaian A, et al. Mortality rate and predicting factors of traumatic thoracolumbar spinal cord injury; a systematic review and meta-analysis. BEAT. 2018;6:181-94.

7. Kopp MA, Watzlawick R, Martus P, Failli V, Finkenstaedt FW, Chen $\mathrm{Y}$, et al. Long-term functional outcome in patients with acquired infections after acute spinal cord injury. Neurology. 2017;88:892-900.

8. Ekeke ON, Okonta KE. Trauma: a major cause of death among surgical inpatients of a Nigerian tertiary hospital. Pan Afr Med J. 2017. https://doi.org/10.11604/pamj.2017.28.6.10690.

9. Kahl JE, Calvo RY, Sise MJ, Sise CB, Thorndike JF, Shackford SR. The changing nature of death on the trauma service. J Trauma Acute Care Surg. 2013;75:195-201.

10. Thietje R, Pouw MH, Schulz AP, Kienast B, Hirschfeld S. Mortality in patients with traumatic spinal cord injury: descriptive analysis of 62 deceased subjects. J Spinal Cord Med. 2011;34:482-7.

11. Lidal I, Snekkevik H, Aamodt G, Hjeltnes N, Biering-Sørensen F, Stanghelle J. Mortality after spinal cord injury in Norway. J Rehabilit Med. 2007;39:145-51.

12. Mirzaeva L, Gilhus NE, Lobzin S, Rekand T. Incidence of adult traumatic spinal cord injury in Saint Petersburg, Russia. Spinal Cord. 2019;57:692-9.

13. Hagen EM, Eide GE, Rekand T, Gilhus NE, Gronning M. A 50year follow-up of the incidence of traumatic spinal cord injuries in Western Norway. Spinal Cord. 2010;48:313-8.

14. Ferro S, Cecconi L, Bonavita J, Pagliacci MC, Biggeri A, Franceschini M. Incidence of traumatic spinal cord injury in Italy during 2013-4: a population-based study. Spinal Cord. 2017:55:1103-7.

15. McCaughey EJ, Purcell M, McLean AN, Fraser MH, Bewick A, Borotkanics RJ, et al. Changing demographics of spinal cord 
injury over a 20-year period: a longitudinal population-based study in Scotland. Spinal Cord. 2016;54:270-6.

16. Schedrenok V, Orlov S, Anikeev N, Krasnoshlyk P, Sovakov I, Moguchaya O. Epidemiology and quality of medical aid in combined column-spinal cord trauma in some regions of Russion Federation [in Russian]. Neurochirurgia. 2010;11:458-66.

17. Biering-Sørensen F, DeVivo MJ, Charlifue S, Chen Y, New PW, Noonan V, et al. International Spinal Cord Injury Core Data Set (version 2.0) - including standardization of reporting. Spinal Cord. 2017;55:759-64.

18. van Weert KCM, Schouten EJ, Hofstede J, van de Meent H, Holtslag HR, van den Berg-Emons RJG. Acute phase complications following traumatic spinal cord injury in Dutch level 1 trauma centres. J Rehabilit Med. 2014;46:882-5.

19. Joseph C, Nilsson Wikmar L. Prevalence of secondary medical complications and risk factors for pressure ulcers after traumatic spinal cord injury during acute care in South Africa. Spinal Cord. 2016;54:535-9.

20. Boakye M, Patil CG, Santarelli J, Ho C, Tian W, Lad SP. Laminectomy and fusion after spinal cord injury: national inpatient complications and outcomes. J Neurotrauma. 2008;25: 173-83.

21. Brienza D, Krishnan S, Karg P, Sowa G, Allegretti AL. Predictors of pressure ulcer incidence following traumatic spinal cord injury: a secondary analysis of a prospective longitudinal study. Spinal Cord. 2018;56:28-34.

22. Marion TE, Rivers CS, Kurban D, Cheng CL, Fallah N, Batke J, et al. Previously identified common post-injury adverse events in traumatic spinal cord injury-validation of existing literature and relation to selected potentially modifiable comorbidities: a prospective canadian cohort study. J Neurotrauma. 2017;34:2883-91.

23. Nulle A, Tjurina U, Erts R, Vetra A. A profile of traumatic spinal cord injury and medical complications in Latvia. Spinal Cord Ser Cases. 2017. https://doi.org/10.1038/s41394-017-0002-2.
24. Yuldashev S, Hasanov A, Nigmatullin R. Prevention of urological complications in patients with spinal injury [in Russian]. Vestnik Khirurgii. 2007;166:39-42.

25. Grin' A, Nekrasov M, Kajkov AK, Oshchepkov S, L'vov I, Ioffe $\mathrm{Y}$, et al. Algorithms for the diagnosis and treatment of patients with combined spinal cord injury [in Russian]. Hir Pozvonoc. 2012;9:8-18.

26. Maung AA, Schuster KM, Kaplan LJ, Maerz LL, Davis KA. Risk of venous thromboembolism after spinal cord injury: not all levels are the same. J Trauma. 2011;71:1241-5.

27. Hagen EM, Eide GE, Rekand T, Gilhus NE, Gronning M. Traumatic spinal cord injury and concomitant brain injury: a cohort study: traumatic spinal cord injury and concomitant brain injury. Acta Neurol Scand. 2010;122:51-7.

28. Bombardier CH, Lee DC, Tan DL, Barber JK, Hoffman JM. Comorbid traumatic brain injury and spinal cord injury: screening validity and effect on outcomes. Arch Phys Med Rehabilit. 2016;97:1628-34.

29. Crutcher CL, Ugiliweneza B, Hodes JE, Kong M, Boakye M. Alcohol intoxication and its effects on traumatic spinal cord injury outcomes. J Neurotrauma. 2014;31:798-802.

30. Krause JS, Carter RE, Pickelsimer EE, Wilson D. A prospective study of health and risk of mortality after spinal cord injury. Arch Phys Med Rehabilit. 2008;89:1482-91.

31. Barinov A, Kondakov E. Survival and mortality in acute spinal cord injury in the Arkhangelsk region [In Russian]. Hum Ecol. 2011;8:51-5.

32. Garshick E, Kelley A, Cohen SA, Garrison A, Tun CG, Gagnon $\mathrm{D}$, et al. A prospective assessment of mortality in chronic spinal cord injury. Spinal Cord. 2005;43:408-16.

33. Eichinger S, Eischer L, Sinkovec H, Wittgruber G, Traby L, Kammer M, et al. Risk of venous thromboembolism during rehabilitation of patients with spinal cord injury. PLoS ONE. 2018;13:1-10. 